\title{
Alzheimer disease biomarker detection through electrocatalytic water oxidation induced by iridium oxide nanoparticles
}

Lourdes Rivas, ${ }^{\text {a,b }}$ Alfredo de la Escosura-Muñiz, ${ }^{a}$ Josefina Pons ${ }^{\mathrm{b}}$ and Arben Merkoçi ${ }^{\mathrm{a}, \mathrm{c}^{*}}$

aCN2 - Institut Catala de Nanociencia i Nanotecnologia, Campus UAB, 08193 Bellaterra (Barcelona), Spain

bDepartment de Química, Universitat Autónoma de Barcelona, 08193, Bellaterra (Barcelona), Spain

'ICREA - Institucio Catalana de Recerca i Estudis Avançats, 08010 Barcelona, Spain

*Corresponding author: arben.merkoci@icn.cat Tel: +34937374604

This is the peer reviewed version of the following article: Rivas, L. et al. Alzheimer disease biomarker detection through electrocatalytic water oxidation induced by iridium oxide nanoparticles in Electroanalysis, vol. 26, issue 6 (June 2014), p. 1287-1294, which has been published in final form at DOI 10.1002/elan.201400027. This article may be used for noncommercial purposes in accordance with Wiley terms and conditions for use of self-Archived versions. 


\section{Abstract}

Iridium oxide nanoparticles $\left(\mathrm{IrO}_{2} \mathrm{NPs}\right)$ synthetized following a previously reported chemical route are presented as novel tags for immunosensing taking advantage of their electrocatalytic activity towards water oxidation reaction (WOR). Cyclic voltammetry and chronoamperometry for the evaluation of the $\mathrm{IrO}_{2} \mathrm{NPs}$ electrocatalytic activity towards WOR at neutral $\mathrm{pH}$ were used. The chronoamperometric current recorded at a fixed potential of $+1.3 \mathrm{~V}$ constituted the analytical signal allowing the quantification of $\mathrm{IrO}_{2} \mathrm{NPs}$ at $\mathrm{nM}$ levels. Modification of the surface of citrate-capped $\mathrm{IrO}_{2}$ NPs with anti-Apolipoprotein $\mathrm{E}$ antibodies ( $\alpha$-ApoE) was successfully achieved and the as-prepared conjugates were used for the electrocatalytic detection of ApoE Alzheimer disease (AD) biomarker in a magnetosandwich immunoassay, reaching a detection limit of $68 \mathrm{ng} / \mathrm{mL}$. Human plasma of a patient suffering AD was also evaluated, estimating an ApoE concentration of $20 \mu \mathrm{g} / \mathrm{mL}$ which is in concordance with the obtained in previously reported approaches. This novel $\mathrm{IrO}_{2} \mathrm{NPs}$ based electrocatalytic assay presents the advantage of the signal generation in the same medium where the immunoassay takes place (PBS, pH 7.4) avoiding the use of additional reagents which also opens the way to future integrated biosensing systems and platforms with interest for other proteins as well as DNA and cells analysis.

Keywords: iridium oxide nanoparticles, electrocatalytic activity, water oxidation reaction (WOR), diagnostics, ApoE, Alzheimer. 


\section{Introduction}

Recent advances in materials science and, in particular, in the nanomaterials field have opened the way to great achievements in immunosensing technology. Outstanding optical and electrochemical properties of nanoparticle tags have been extensively studied and applied for immunosensing in the last years, offering excellent alternatives to existing conventional strategies/assays with interest in different fields, being the early diagnostics based on sensitive detection of protein biomarkers the most relevant one.[1-7] Of special interest is the possibility to electrochemically detect NP tags, due to the inherent advantages of the electrochemical techniques in terms of sensitivity, selectivity, low cost and ease of use mode, together with the possibility of miniaturization of the detection system.[8-10] NPs such as gold NPs (AuNPs) and quantum dots NPs (QDs) have been used as labels for protein biomarkers detection due to their excellent redox properties, electrocatalytic activity toward several substrates and easy preparation and bioconjugation capabilities.[11,12] However, these approaches often suffer the limitation related to the need of acidic solutions either for the total dissolution of the NP tag followed by stripping voltammetric detection[13-16] or as source of protons for further electrocatalytic detection based on the hydrogen evolution reaction (HER).[17-19] The use of such acidic solutions, in addition to inherent security risks, represents an additional step which not only increases the analysis time but also is a crucial limitation in case of really integrated sensing systems, such as those based on lab-on-a-chip or lateral-flow platforms. Hydrogen bubbles formed during hydrogen gas evolution is another inconvenience for the integration of HER based biosensing systems in microfluidics platforms. For these reasons, there is a demand for novel NP tags easy to be detected in the same medium of the immunoreaction, often saline buffers at neutral $\mathrm{pH}$. In this context we consider that NPs able to catalyze water oxidation reaction (WOR) would be ideal candidates for this purpose.

Electrochemical water splitting is composed of two half-cells redox reactions which have been studied separately.[20] While the HER proceeds in two-electron process, the evolution of oxygen from water, WOR, is a more complex endothermic process $\left(\mathrm{E}^{\mathrm{o}}=1.23 \mathrm{eV}\right.$ at $\left.\mathrm{pH} 0.0\right)$ that involves four electrons and formation of an oxygen-oxygen bond.

$$
2 \mathrm{H}_{2} \mathrm{O} \rightarrow \mathrm{O}_{2}+4 \mathrm{H}^{+}+4 \mathrm{e}^{-} \quad \text { Eq. } 1
$$


In nature, the photosynthetic water oxidation is catalyzed by a Mn complex in a membrane protein complex located in photosynthetic organisms.[21,22] Due to its importance, many studies have been carried out so as to understand the mechanism of water splitting and oxygen formation driven naturally.[23] Molecular complexes based on $\mathrm{Ru}[24-26], \mathrm{Mn}[27,28], \mathrm{Ir}[29,30]$; bulk metal oxides of $\mathrm{Co}_{3} \mathrm{O}_{4}[31,32], \quad \mathrm{RuO}_{2}$ and $\mathrm{IrO}_{2}[33]$ and moreover, their nanoparticulated metal oxides[34-38] have been studied in the pursuit of a synthetic catalyst capable to effectively oxidize water. In this context, $\mathrm{IrO}_{2}$ is a very attractive material to be considered thanks to its catalytic activity, biocompatibility, low resistivity and outstanding chemical and thermal stability which has been used for applications in $\mathrm{pH}$ sensors[39,40] and neural stimulation.[41,42]

It is well known that nanomaterials exhibit a large surface area that leads to an increase in their reactivity, compared with the bulk material. Due to this property, the catalytic activity of iridium oxide nanoparticles ( $\mathrm{IrO}_{2} \mathrm{NPs}$, stabilized by citrate ions) towards water oxidation reaction, has been tested under photochemical conditions with strong oxidants showing a good catalytic performance.[34,35,43] Citrate capped $\mathrm{IrO}_{2} \mathrm{NPs}$ showed a remarkable catalytic activity toward the WOR when they were self-assembled on an indium tin oxide (ITO) forming an ester layer on the electrode.[36]

All these noteworthy features make $\mathrm{IrO}_{2} \mathrm{NPs}$ ideal candidates for using in biosensing field. However, to the best of our knowledge, neither the electrocatalytic activity of $\mathrm{IrO}_{2} \mathrm{NPs}$ in suspension nor their use as tags in biosensing have not been yet evaluated. Their easy to be measured electrocatalytic properties at neutral $\mathrm{pH}$ opens the way to their direct detection in the same medium where the immunoreaction takes place (i.e. PBS buffer, $\mathrm{pH}$ 7.4), overcoming the above mentioned limitations of other NP-based electrochemical immunosensing systems.

In this work we explore the excellent electrocatalytic property of $\mathrm{IrO}_{2} \mathrm{NPs}$ toward WOR and employ this as a new signaling route in protein diagnostics. Magnetic beads modified with antibodies are used as platforms of the immunoassay which is applied for the detection of Apolipoprotein E (ApoE), a well-established biomarker of Alzheimer disease (AD) $[44,45]$ which is one of the most common cause of dementia. The use of this novel label is expected to allow a simpler and user-friendlier methodology for biomarkers detection and also to open the way to future integrated biosensing systems and platforms.

\section{Experimental}




\subsection{Materials and apparatus}

Potassium hexachloroiridate (IV) $\left(\mathrm{K}_{2} \mathrm{IrCl}_{6}\right)$, sodium hydrogen citrate sesquihydrate $\left(\mathrm{Na}_{2} \mathrm{C}_{6} \mathrm{H}_{6} \mathrm{O}_{7} \cdot 1.5 \mathrm{H}_{2} \mathrm{O}\right)$, sodium hydroxide $(\mathrm{NaOH}) ; \mathrm{N}$-(3-Dimethylaminopropyl)- $\mathrm{N}^{\prime}$-ethylcarbodiimide hydrochloride (EDC), $\mathrm{N}$ Hydroxysulfosuccinimide sodium salt (sulpho-NHS), phosphate buffer saline in tablet, 2-( $N$ morpholino)ethanesulfonic acid (MES buffer), Tween 20, bovine serum albumin (BSA), were purchased from Sigma Aldrich. Carboxyl-modified magnetic beads $2.8 \mu \mathrm{m}$ sized (MBs) were purchased from Dynal Biotech. (Dynabeads ${ }^{\circledR}$ M-270, Invitrogen). Capture monoclonal antibody, biotinylated detection mAb, streptavidin-enzyme conjugate HRP and purified ApoE as a standard were purchased from Mabtech. mQ water, produced using a Milli-Q system (>18.2 ${\mathrm{M} \Omega \mathrm{cm}^{-1}}^{-1}$ purchased from Millipore, was used for the preparation of all solutions. The stirrer used was a TS-100 Thermo shaker (BioSan). A thermostatic centrifuge (Sigma 2-16 PK, Fisher Bioblock Scientific) was used to purify the iridium oxide nanoparticles/antibody conjugates.

Human plasma samples of a patient suffering from Alzhemier disease were provided by the Institute of Neurology of Ulm University (Germany).

The electrochemical transducers used were homemade screen-printed carbon electrodes (SPCEs) and the measurements were performed using a home-made methacrylate cell connected to an Autolab 20 (Ecochemie). See the detailed SPCE fabrication procedure at the Supporting Information.

\subsection{Synthesis and characterization of iridium oxide nanoparticles ( $\left(\mathrm{rrO}_{2} \mathrm{NPs}\right)$}

The procedure for the synthesis of iridium oxide nanoparticles is based on Harriman work. [34] Briefly, 30 $\mathrm{mg}$ of $\mathrm{K}_{2} \mathrm{IrCl}_{6}$ were added to $50 \mathrm{~mL}$ aqueous solution of $3.8 \mathrm{mM}$ sodium hydrogen citrate. The resulting redbrown solution was adjusted to $\mathrm{pH} 7.5$ using a $0.25 \mathrm{M} \mathrm{NaOH}$ solution and then refluxed with constant stirring for $30 \mathrm{~min}$. After this, the solution changed its color to a light blue and it was cooled at room temperature and the $\mathrm{pH}$ of the solution was again adjusted to 7.5. Then, it was stirred and refluxed for $30 \mathrm{~min}$. These steps were repeated until obtaining a constant value of $\mathrm{pH} 7.5$. The solution was additionally refluxed for 2 $\mathrm{h}$ with oxygen bubbling through the solution to yield a deep blue suspension of $\mathrm{IrO}_{2} \mathrm{NPs}$ (see Figure $\mathrm{S} 2$ at the Supporting Information). All the experiments were conducted with the as-prepared solution that was stored at $4^{\circ} \mathrm{C}$. 
The total amount of iridium in the NPs suspension was obtained by analysis with inductively coupled plasma-optical emission spectrometry (ICP-OES) at the Servei d'Anàlisi Química of the Universitat Autónoma de Barcelona. Samples were diluted in aqua regia in a microwave digester (CEM Corporation, model MARSXpress) and inserted in the ICP-OES spectrometer (Perkin-Elmer, model Optima 4300DV) to obtain the total content of iridium, expressed in $\mathrm{mg} / \mathrm{L}$.

All the sizing measurements and shape characterization of $\mathrm{IrO}_{2} \mathrm{NPs}$ were conducted in a Field Emission Gun Transmission Electronic Microscope (Fei, model Tecnai ${ }^{\mathrm{TM}} \mathrm{G} 2 \mathrm{~F} 20$ ). For the sample preparation, $5 \mu \mathrm{L}$ of the as-prepared $\mathrm{IrO}_{2} \mathrm{NPs}$ dispersion were dropped on a copper grid and let to be dried all the night.

X-ray photoelectron spectroscopy (XPS) experiments were carried out in the Centres Cientifics I Tecnològics of the Universitat de Barcelona (CCiTUB) and were performed with a PHI 5500 Multitechnique System (Physical Electronics) with a monochromatic X-ray source (Aluminium $\mathrm{K} \alpha$ line of $1486.6 \mathrm{eV}$ energy and $350 \mathrm{~W}$ ), placed perpendicularly to the analyzer axis and calibrated using the $3 \mathrm{~d}_{5 / 2}$ line of Ag with a full width at half maximum (FWHM) of $0.8 \mathrm{eV}$. All measurements were made in an ultra-high vacuum (UHV) chamber pressure between $5 \times 10^{-9}$ and $2 \times 10^{-8}$ torr. Binding energies were calibrated respect to the $\mathrm{C} 1 \mathrm{~s}$ electron peak at $284.8 \mathrm{eV}$.

\subsection{Conjugation of $\mathrm{IrO}_{2} \mathrm{NPs}$ to $\alpha \mathrm{ApoE}$ antibodies}

The $\alpha$ ApoE antibodies immobilization on $\mathrm{IrO}_{2} \mathrm{NPs}$ was performed by direct random adsorption onto the NP surface. Briefly, $100 \mu \mathrm{L}$ of $100 \mu \mathrm{g} / \mathrm{mL} \alpha \mathrm{ApoE}$ monoclonal antibody ( $\alpha \mathrm{ApoE} \mathrm{mAb}$ ) were added to $1.75 \mathrm{~mL}$ of $\mathrm{IrO}_{2} \mathrm{NPs}$ suspension adjusted to $\mathrm{pH}$ 7. The resulting solution was incubated for $20 \mathrm{~min}$ at $650 \mathrm{rpm}$. Then, $150 \mu \mathrm{L}$ of $5 \%$ w/v BSA aqueous solution were added and the stirring was continued for other $20 \mathrm{~min}$ at 650 rpm. Finally, the solution was centrifuged at $35000 \times \mathrm{g}\left(4^{\circ} \mathrm{C}\right)$ for 2 hours and 30 minutes. The supernatant was removed and the pellet of iridium oxide NP/ $\alpha \mathrm{ApoE}$ mAb was re-suspended in $200 \mu \mathrm{L}$ of milliQ water.

The same experimental procedure was previously followed for the conjugation of anti-human IgGhorseradish peroxidase ( $\alpha \mathrm{HIgG}-\mathrm{HRP}$ ) antibodies to $\mathrm{IrO}_{2} \mathrm{NPs}$ so as to check the antibody immobilization on the NPs surface. This study was performed by the addition of TMB solution (that acts as HRP substrate) to suspensions of $\mathrm{IrO}_{2} \mathrm{NPs}$ conjugates at different $\mathrm{pH}$ values ( $\mathrm{pH}$ 7, 8 and 9). Typical change of color from colorless to blue was observed when the reaction between the TMB and the HRP labelling the antibodies 
took place, corresponding to the generation of a cation free-radical as oxidation product. The reaction was stopped by adding $\mathrm{H}_{2} \mathrm{SO}_{4}$, observing a stronger coloration for the conjugates prepared at $\mathrm{pH} 7$ (see figure S3 at the Supporting Information), so these conditions were chosen for the preparation of the conjugate between $\mathrm{IrO}_{2} \mathrm{NPs}$ and the $\alpha \mathrm{ApoE}$ antibody.

\subsection{Magnetosandwich immunoassay for ApoE capturing and labelling with $\mathrm{IrO}_{2} \mathrm{NPs}$}

Carboxylated magnetic microbeads were functionalized through the well-known EDC/sulfo-NHs chemistry. EDC was pre-activated by mixing $133 \mu \mathrm{L}$ of EDC $(10 \mathrm{mg} / \mathrm{mL})$ with $25 \mu \mathrm{L}$ of sulfo-NHS $(100 \mathrm{mg} / \mathrm{mL})$ for 10 min (both solutions in $100 \mathrm{mM}$ MES, pH 5). After that, $842 \mu \mathrm{L}$ of $10 \mathrm{mM}$ MES $\mathrm{pH} 5$ were added forming solution 1. $15 \mu \mathrm{L}$ of carboxylated magnetic beads were placed in an Eppendorf tube, washed two times in MES buffer and reconstituted in $150 \mu \mathrm{L}$ of the solution 1 . The mixture was incubated at $37^{\circ} \mathrm{C}$ for $30 \mathrm{~min}$ (700 rpm). Oriented antibody immobilization was performed by adapting a procedure previously optimized in our group.[46] Briefly, after washing two times in MES buffer, $30 \mu \mathrm{L}$ of a $300 \mu \mathrm{g} / \mathrm{mL}$ monoclonal goat $\alpha$ ApoE antibody solution and $120 \mu \mathrm{L}$ of $10 \mathrm{mM}$ MES, $\mathrm{pH}$ 5, were added to the microspheres and incubated at $37{ }^{\circ} \mathrm{C}$ for $1 \mathrm{~h}(700 \mathrm{rpm})$. After washing two times in MES buffer, $150 \mu \mathrm{L}$ of $5 \%$ BSA (in MES buffer) were added to the microspheres and incubated first at $25^{\circ} \mathrm{C}$ for $20 \min (700 \mathrm{rpm})$ and then at $4{ }^{\circ} \mathrm{C}$ overnight.

After washing two times in PBS-Tween buffer and once in PBS buffer, $150 \mu \mathrm{L}$ of recombinant ApoE standard in PBS buffer was added to the microspheres and incubated at $25^{\circ} \mathrm{C}$ for 20 min $(700 \mathrm{rpm})$. After washing two times in PBS-Tween buffer and once in PBS buffer, $150 \mu \mathrm{L}$ of the previously synthesized $\mathrm{IrO}_{2}$ NPs/ $\alpha$ ApoE antibody were added to the microspheres and incubated at $25^{\circ} \mathrm{C}$ for $20 \mathrm{~min}(700 \mathrm{rpm})$. The magnetic conjugate was washed four times in PBS-Tween 20 buffer, two times in PBS, once in water and reconstituted in $150 \mu \mathrm{L}$ of $0.1 \mathrm{M}$ PBS.

In the case of the analysis of human plasma samples, the same experimental procedure was followed, using serial diluted plasma samples in PBS buffer instead of the standard of ApoE.

\subsection{Electrochemical measurements}

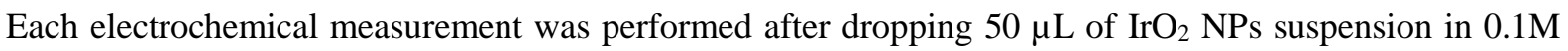
PBS pH 7.4 freshly prepared onto the SPCE. Blank signals were recorded following the same electrochemical procedure but using an aliquot of buffer. Cyclic voltammetry (CV) was carried out from - 
$0.5 \mathrm{~V}$ to $+1.3 \mathrm{~V}$ at $50 \mathrm{mV} \mathrm{s}^{-1}$ and chronoamperometry was performed at a fixed potential of $+1.3 \mathrm{~V}$ during $300 \mathrm{~s}$.

The electrochemical detection of ApoE captured through the magnetosandwich immunoassay was evaluated through the water oxidation reaction. Briefly, $50 \mu \mathrm{L}$ of the immunocomplex suspension were placed on the surface of the screen-printed carbon electrode (SPCE), where a magnet was previously attached to polyester on the reverse side of the working area. An oxidative potential of $+1.3 \mathrm{~V}$ was applied during $300 \mathrm{~s}$. The water oxidation catalyzed by the $\mathrm{IrO}_{2}$ NPs tags was chronoamperometrically followed measuring the current generated during the time. The absolute value of the current at $250 \mathrm{~s}$ was chosen as the analytical signal. For all the experiments, the measurements were made by triplicate at room temperature.

\section{Results and discussion}

\subsection{Characterization of $\mathrm{IrO}_{2} \mathrm{NPs}$}

Characterization of $\mathrm{IrO}_{2} \mathrm{NPs}$ was conducted through different techniques as UV-visible spectrophotometry (UV-Vis), transmission electronic microscopy (TEM) and X-ray photoelectron spectroscopy (XPS). Hydrolysis of hexachloroiridate (IV) ion, $\left[\mathrm{IrCl}_{6}\right]^{2-}$, in neutral aqueous solutions in the presence of citrate ions, results in formation of deep blue suspension of nanoparticles of $\mathrm{IrO}_{2} . x \mathrm{H}_{2} \mathrm{O}[34]$ (for simplicity, they will be denoted as $\mathrm{IrO}_{2}$ ). TEM micrographs reveal the homogeneous distribution of $\mathrm{IrO}_{2} \mathrm{NPs}$ (see Figure 1) and is worthy to note the homogeneous size of observed agglomerates of $12.5 \pm 2.5 \mathrm{~nm}$ composed by smaller nanoparticles of $1.5 \pm 0.3 \mathrm{~nm}$. This suggests that the initially formed small nanoparticles quickly form bigger agglomerates. This behavior is in agreement with previously reported studies.[35,47]

UV-Vis spectrum of $\mathrm{IrO}_{2}$ NPs is shown in Figure 1B, where a broad peak between 500-700nm with maximum at $590 \mathrm{~nm}$, characteristic of $\mathrm{Ir}(\mathrm{IV})$ oxides and $\mathrm{IrO}_{2} \mathrm{NPs}$ is observed.[34]

XPS analyses were performed in order to confirm the chemical composition of the synthesized $\mathrm{IrO}_{2} \mathrm{NPs}$ (see Figure 1C, left). By deconvoluting the XPS spectra, two binding states for iridium are identified as $4 f_{7 / 2}$ and $4 \mathrm{f}_{5 / 2}$ at 62.3 and $65.1 \mathrm{eV}$, respectively. These peaks are attributed to the $4+$ oxidation state of iridium and they are similar to those of $\mathrm{IrO}_{2}$ nanorods $\left(62.0\right.$ and $65.0 \mathrm{eV}$ ) and similar to $\mathrm{IrO}_{2}$ single crystal (which has values of 61.7 and $64.7 \mathrm{eV}$ ).[48] Regarding the oxygen 1s signal, a main peak at 531.6 and a small one 
at $533.7 \mathrm{eV}$ were observed as shown in figure $1 \mathrm{C}$ (right). The former is similar to the value found for $\mathrm{IrO}_{2}$ nanorods and $\mathrm{IrO}_{2}$ single crystal, both at $530.5 \mathrm{eV}$.[48] The broader feature at $533.7 \mathrm{eV}$ might be attributed to the oxygen-containing citrate coating these nanoparticles.

According to the mentioned characterization, especially with the XPS analyses, it is possible to conclude that the deep-blue suspension synthetized corresponds to $\mathrm{IrO}_{2}$ nanoparticles.

The concentration of iridium oxide stock solution was calculated to be around $35 \mathrm{nM}$ using the concentration of Ir obtained by ICP-OES $(0.227 \mathrm{mg} / \mathrm{mL} ; 1.18 \mathrm{mM})$ divided by the number of atoms per particle $(\mathrm{N})$ as stated in Supporting Information.

\subsection{Electrocatalytic activity of $\mathrm{IrO}_{2}$ NPs towards WOR}

The electrocatalytic activity of $\mathrm{IrO}_{2} \mathrm{NPs}$ towards water oxidation reaction was first evaluated by cyclic voltammetry (CV) using screen-printed carbon electrodes (SPCE).

$\mathrm{CV}$ voltammograms were conducted in $0.1 \mathrm{M}$ PBS $\mathrm{pH} 7.4$ and obtained by scanning from +0.1 to $+1.3 \mathrm{~V}$ at $50 \mathrm{mV} / \mathrm{s}$ scan rate. The as-performed voltammograms for different concentrations of $\mathrm{IrO}_{2} \mathrm{NPs}$ in $0.1 \mathrm{MPBS}$ are shown in figure 2A. The background curve (a) shows that the oxidation of the medium's oxygen starts at approximately $+1.10 \mathrm{~V}$. In the presence of the $\mathrm{IrO}_{2} \mathrm{NPs}$ (curves b-e) on the surface of the electrode, the potential for water oxidation shifts (by up to $300 \mathrm{mV}$, depending on the concentration of $\mathrm{IrO}_{2} \mathrm{NPs}$ ) toward less positive potentials. Moreover, it can also be seen that, because of the catalytic effect of the $\mathrm{IrO}_{2} \mathrm{NPs}$, a higher current is generated (up to $70 \mu \mathrm{A}$ higher, as evaluated for the potential value of $+1.3 \mathrm{~V}$, depending on the concentration of $\mathrm{IrO}_{2} \mathrm{NPs}$ ). A shift in the half-wave potential of the WOR to less positive potentials from $1.1 \mathrm{~V}$ to up to $0.77 \mathrm{~V}$ (maximum shift of $332 \mathrm{mV}$ ) which is proportional to the quantity of $\mathrm{IrO}_{2} \mathrm{NPs}$ due to their catalytic effect towards this reaction can also be observed in the same figure.

The obtained results show that, for a fixed potential (i.e., $+1.3 \mathrm{~V}$ at which steady state currents values are achieved), the intensity of the current recorded in chronoamperometric mode during the stage of oxygen electro-oxidation (Figure 2B) can be related to the presence (curves b'-e') or absence (curve a') of $\mathrm{IrO}_{2} \mathrm{NPs}$ on the surface of the SPCE. A proportional increase of the catalytic current for increasing concentrations of $\mathrm{IrO}_{2} \mathrm{NPs}$ (from 0.7 to $35 \mathrm{nM}$ ) was observed. 
Regarding the fixed interval of time selected for the current recording (analytical signal), it was observed that for intervals shorter than $250 \mathrm{~s}$ the current profiles were not reproducible. Looking at the behavior during the first $50 \mathrm{~s}$, a rapid decrease in the anodic current was observed, probably due to an initial rapid oxidation of water on the surface of the $\mathrm{IrO}_{2}$ NPs catalyzers followed by a current stabilization. This effect is more evident for higher $\mathrm{IrO}_{2} \mathrm{NPs}$ concentrations (curves d' and e'). The observed irreproducibility during the 50$250 \mathrm{~s}$ range could be attributed to the fact that $\mathrm{IrO}_{2} \mathrm{NPs}$ are still not accommodated onto the electrode surface being still under Brownian motions (stabilization time). The current value was stable in all cases after 250 $\mathrm{s}$, so registering at this time interval was chosen as analytical signal.

A logarithmic relationship between the analytical signal and the concentration of $\mathrm{IrO}_{2} \mathrm{NPs}$ in the range of $0.7-35 \mathrm{nM}$ adjusted to the following equation:

$$
\text { Current }(\mu \mathrm{A})=3.15 \ln \left[\mathrm{IrO}_{2} \mathrm{NPs}\right]+8.13 \text { Eq. } 2
$$

showing a good correlation $(\mathrm{r}=0.98)$ and a relative standard deviation of $5.6 \%$ for $7 \mathrm{nM}$ of $\operatorname{IrO}_{2} \mathrm{NPs}(n=3)$. The limit of detection was calculated as the concentration of $\mathrm{IrO}_{2} \mathrm{NPs}$ corresponding to three times the standard deviation of the estimated, giving a value of $0.13 \mathrm{nM}$.

\subsection{Electrocatalytic detection of ApoE Alzheimer disease biomarker in human plasma}

Magnetic beads were used as platforms of the immunoassays for ApoE detection, taking advantage of their well-known characteristics for capturing/pre-concentrating the analyte and minimizing matrix effects. Carboxylated magnetic beads were modified with $\alpha$ ApoE antibody using the EDC-sulpho-NHS coupling. First, EDC was used in order to activate the carboxylic groups located on the surface of magnetic beads. Then, addition of sulpho-NHS led to formation of a stable sulpho-ester, which reacts with the amine groups located in the antibody, allowing forming of the $\alpha$ ApoE modified magnetic beads ( $\alpha$ ApoE-MB). Blocking with BSA is performed in order to avoid unspecific absorptions onto the surface of the electrotransducer. When ApoE is present in the sample, it is recognized by the $\alpha \mathrm{ApoE}$ antibody forming the ApoE/ $\alpha$ ApoEMB complex. 
Once the washing step is performed, the conjugate of $\alpha \mathrm{ApoE}-\mathrm{IrO}_{2} \mathrm{NPs}$ is able to recognize the ApoE , forming the magnetosandwich $\alpha \mathrm{ApoE}-\mathrm{IrO}_{2} \mathrm{NPs} / \mathrm{ApoE} / \alpha \mathrm{ApoE}-\mathrm{MB}$, being the amount of $\mathrm{IrO}_{2} \mathrm{NPs}$ proportional to the ApoE concentration in the sample.

Electrochemical detection of ApoE was carried out using $50 \mu \mathrm{L}$ of the immunocomplex suspension placed onto the surface of the SPCE and taking advantage of the electrocatalytic properties of $\mathrm{IrO}_{2} \mathrm{NPs}$ towards WOR. The catalytic behavior of the $\mathrm{IrO}_{2} \mathrm{NPs}$ generated by the oxidation of water is conducted by chronoamperometry and correlated to the amount of the ApoE in the sample. Figure 4A shows the chronoamperograms obtained for samples containing 0 (a), 100 (b), 200 (c), 500 (d) and 1000 (e) ng/mL of ApoE. As expected, the catalytic current increases when the concentration of ApoE increases. The relationship between the concentration of ApoE in the sample and the value of the analytical signal (current recorded at 250s) is adjusted to a logarithmic curve, as shown in Figure 4B. The curve exhibits a good correlation ( $\mathrm{r}=0.98)$ in the range of $100-1000 \mathrm{ng} / \mathrm{mL}$, adjusted to the following equation:

$$
\text { Current }(\mu \mathrm{A})=2.64[\text { ApoE }(\mathrm{ng} / \mathrm{mL})]-10.94 \quad \text { Eq. } 3
$$

The limit of detection, calculated as stated before, gives a value of $68 \mathrm{ng} / \mathrm{mL}$. The reproducibility of the responses $(n=3)$ for $500 \mathrm{ng} / \mathrm{mL}$ of ApoE shows a relative standard deviation of $6 \%$.

Finally, a human plasma sample with an unknown concentration of ApoE was electrocatalytically analyzed. As ApoE concentration in plasma typically ranges from 16 to $169 \mu \mathrm{g} / \mathrm{mL}$,[49] very small volumes of plasma were diluted in PBS buffer before analysis. A dilution of the sample of 1:1000 was necessary to obtain a current within the linear range of the method, obtaining a value of $3.08 \pm 0.18 \mu \mathrm{A}(n=3)$ for such a dilution. Extrapolating this value from Eq. 3, a concentration of ApoE of $20 \pm 2 \mu \mathrm{g} / \mathrm{mL}$ was estimated in the sample. Matrix effects are not relevant in our assay due to two main factors. First of all, possible interfering substances are highly diluted in the analyzed sample (1:1000). Furthermore, and more importantly, the use of magnetic bead platforms modified with an specific antibody allow us to capture the ApoE protein and then separate the magnetic bead/ApoE complex from the matrix of the sample, thanks to the use of a magnetic field. Magnetic beads are conveniently blocked before with BSA so as to avoid unspecific absorptions. The final measurements are performed in PBS buffer, so not background contributions are neither found at the $+1.3 \mathrm{~V}$ voltage applied. 
The obtained results are in concordance with the above mentioned expected data and also with those previously obtained in our group using both microarray technology[50] and electrochemical detection[51] based on commercial Quantum Dot tags. 


\section{Conclusions}

Iridium oxide nanoparticles ( $\mathrm{IrO}_{2} \mathrm{NPs}$ ) of $12 \mathrm{~nm}$ size were successfully synthesized, characterized and used as novel electrocatalytic tags for immunosensing. The stable NPs suspension exhibited a high catalytic effect towards the Water Oxidation Reaction (WOR), allowing their sensitive quantification at neutral $\mathrm{pH}$ in a simple chroroamperometric mode. This sensitive method was applied for the evaluation of ApoE in human plasma following an immunoassay format using $\mathrm{IrO}_{2} \mathrm{NPs}$ as advantageous tags, able to be detected in the same buffer where the immunoreaction takes place.

Both the $\mathrm{IrO}_{2}$ NPs tags and electrocatalytic detection method present many advantages compared with previously reported ones based on quantum dots (QDs) or Hydrogen Evolution Reaction (HER). On the one hand, the NP synthesis procedure is simpler and cheaper than i.e. the required for QDs preparation. Furthermore, the chronoamperometric detection based on the WOR is a simple, sensitive and quantitative methodology that can be performed in the same medium of the immunoreaction, avoiding the addition of acidic and hazardous solutions, (along with $\mathrm{H}_{2}$ bubbles formation undesired in microfluidics), usually required for electrochemical detection of other NP tags (ex. AuNP using HER). These advantageous properties open the way to further applications in really integrated sensing systems, such as those based on lab-on-a-chip or lateral-flow platforms. Moreover, the UV-Vis absorption band observed at $590 \mathrm{~nm}$ (deep blue color) of the $\mathrm{IrO}_{2} \mathrm{NPs}$ suspension make these NPs excellent candidates for dual electrochemical/optical detection systems in future lateral flow biodetection platforms.

This novel methodology can be extended for the detection of other $\mathrm{AD}$ biomarkers (i.e. $\beta$-amyloid) representing a simple, rapid and sensitive alternative for AD diagnostics. Furthermore, it opens the way to future integrated biosensing systems and platforms with interest for other proteins as well as DNA and cells analysis. 


\section{Acknowledgements}

We acknowledge the support from MINECO (Spain) under project MAT2011-25870, the E.U. under FP7 contract no. 246513 "NADINE". Prod. Dr. Markus Otto from the Institute of Neurology of Ulm University (Germany) is also acknowledged for kindly providing the human serum samples of a patient suffering from Alzheimer disease. 


\section{References}

[1] A. de la Escosura-Muñiz, C. Parolo, A. Merkoçi, Mater. Today 2010, 13, 24.

[2] L. Dykman, N. Khlebtsov, Chem. Soc. Rev. 2012, 41, 2256.

[3] E. C. Dreaden, A. M. Alkilany, X. Huang, C. J. Murphy, M. A. El-Sayed, Chem. Soc. Rev. 2012, 41, 2740.

[4] A. Walcarius, S. D. Minteer, J. Wang, Y. Lin, A. Merkoçi, J. Mater. Chem. B 2013, 1, 4878.

[5] A. Ambrosi, M. T. Castañeda, A. de la Escosura-Muñiz, A. Merkoçi, in Biosensing using nanomaterials-Bionano (Ed.: A. Merkoçi), Wiley-Interscience, New York, 2009, pp. 177-197.

[6] A. Merkoci, A. Ambrosi, A. de la Escosura, B. Pérez, M. Guix, M. Maltez, S. Marin, in Encyclopedia of Analytical Chemistry, (Ed.: R. A. Meyers), John Wiley, Chichester, 2010, pp. $1-26$

[7] A. Merkoci, Biosensensors Bioelectron. 2010, 26, 1164.

[8] A. de la Escosura-Muñiz, A. Ambrosi, A. Merkoçi, Trends Anal. Chem. 2008, 27, 568.

[9] A. Merkoçi, Electroanalysis 2013, 25, 15.

[10] A. Merkoçi, FEBS J. 2007, 274, 310.

[11] A. de la Escosura-Muñiz, A. Merkoçi, Expert Opin. Med. Diagn. 2010, 4, 21.

[12] D. Tang, Y. Cui, G. Chen, Analyst 2013, 138, 981.

[13] M. Dequaire, C. Degrand, B. Limoges, Anal. Chem. 2000, 72, 5521.

[14] N. Zhu, A. Zhang, Q. Wang, P. He, Y. Fang, Electroanalysis 2004, 16, 577.

[15] R. Cui, H. C. Pan, J. J. Zhu, H. Y. Chen, Anal. Chem. 2007, 79, 8494.

[16] J. Wang, G. Li, A. Merkoçi, J. Am. Chem. Soc. 2003, 125, 3214.

[17] M. T. Castañeda, S. Alegret, A. Merkoçi, Electroanalysis 2007, 19, 743.

[18] A. Ambrosi, M. T. Castañeda, A. J. Killard, M. R. Smyth, S. Alegret, A. Merkoçi, Anal. Chem. 2007, 79, 5232.

[19] A. de la Escosura-Muñiz, C. Sánchez-Espinel, B. Díaz-Freitas, A. González-Fernández, M. Maltez-Da Costa, A. Merkoçi, Anal. Chem. 2009, 81, 10268.

[20] H. Dau, C. Limberg, T. Reier, M. Risch, S. Roggan, P. Strasser, ChemCatChem 2010, 2, 724.

[21] T. J. Meyer, Nature 2008, 451, 778 .

[22] Y. Umena, K. Kawakami, J. R. Shen, N. Kamiya, Nature 2011, 473, 55. 
[23] K. S. Joya, Y. F. Joya, K. Ocakoglu, R. van de Krol, Angew. Chemie, Int. Ed. 2013, 52, 10426.

[24] C. Sens, I. Romero, M. Rodríguez, A. Llobet, T. Parella, J. Benet-Buchholz, J. Am. Chem. Soc. 2004, 126, 7798.

[25] S. Romain, L. Vigara, A. Llobet, Acc. Chem. Res. 2009, 42, 1944.

[26] L. Duan, F. Bozoglian, S. Mandal, B. Stewart, T. Privalov, A. Llobet, L. Sun, Nat. Chem. 2012, 4, 418.

[27] P. Kurz, G. Berggren, M. F. Anderlund, S. Styring , Dalt. Trans. 2007, 4258.

[28] E. A. Karlsson, B. L. Lee, T. Akerman, E. Jhonston, M. Kärkäs, J. Sun, Ö. Hannson, J. E. Bäckwall, B. Akerman, Angew. Chemie 2011, 123, 11919.

[29] N. D. McDaniel, F. J. Coughlin, L. L. Tinker, S. Bernhard, J. Am. Chem. Soc. 2008, 130, 210.

[30] H. Junge, N. Marquet, A. Kammer, S. Denurra, M. Bauer, S. Wohlrab, F. Gärtner, M. Pohl, A. Spannenberg, S. Gladiali, M. Beller, Chemistry 2012, 18, 12749.

[31] A. Harriman, I. J. Pickering, J. M. Thomas, P. A. Christensen, J. Chem. Soc. Faraday Trans. I 1988, 84, 2795.

[32] R. N. Singh, D. Mishra, A. S. K. Anindita, A. Singh, Electrochem. commun. 2007, 9, 1369.

[33] S. Trasatti, J. Electroanal. Chem. Interfacial Electrochem. 1980, 111, 125.

[34] A. Harriman, J. M. Thomas, New J. Chem. 1987, 11, 757.

[35] M. Hara, T. E. Mallouk, Chem. Commun. 2000, 1903.

[36] M. Yagi, E. Tomita, S. Sakita, T. Kuwabara, K. Nagai, J. Phys. Chem. B 2005, 109, 21489.

[37] Y. Zhao, E. A. Hernandez-Pagan, N. M. Vargas-Barbosa, J. L. Dysart, T. E. Mallouk, J. Phys. Chem. Lett. 2011, 402.

[38] Y. Lee, J. Suntivich, K. J. May, E. E. Perry, Y. Shao-horn, J. Phys. Chem. Lett. 2012, 3, 399.

[39] D. O’Hare, K. H. Parker, C. P. Winlove, Med. Eng. Phys. 2006, 28, 982.

[40] W. D. Huang, H. Cao, S. Deb, M. Chiao, J. C. Chiao, Sensors Actuators A 2011, 169, 1.

[41] Y. Lu, T. Wang, Z. Cai, Y. Cao, H. Yang, Y. Y. Duan, Sensors Actuators B Chem. 2009, 137, 334.

[42] K. Göbbels, T. Kuenzel, A. van Ooyen, W. Baumgartner, U. Schnakenberg, P. Bräunig, Biomaterials 2010, 31, 1055.

[43] M. Hara, C. C. Waraksa, J. T. Lean, B. A. Lewis, T. E. Mallouk, J. Phys. Chem. A 2000, 104, 5275 .

[44] J. Kim, J. M. Basak, D. M. Holtzman, Neuron 2011, 63, 287. 
[45] I. Reinvang, T. Espeseth, L. T. Westlye, Neurosci. Biobehav. Rev. 2013, 37, 1322.

[46] C. Parolo, A. de la Escosura-Muñiz, E. Polo, V. Grazu, J. De La Fuente, A. Merkoçi, ACS Appl. Mater. Interfaces 2013, 5, 10753.

[47] S. J. Kwon, F. R. Fan, A. J. Bard, J. Am. Chem. Soc. 2010, 132, 13165.

[48] R. S. Chen, Y. Huang, Y. M. Liang, D. S. Tsai, Y. Chi, J. J. Kai, J. Mater. Chem. 2003, 13, 2525.

[49] M. Vicent-Viry, F. Schiele, R. Gueguen, K. Bohnet, S. Visvikis, Clin. Chem. 1998, 44, 957.

[50] E. Moralez-Narváez, H. Montón, A. Fomicheva, A. Merkoçi, Anal. Chem. 2012, 84, 6821.

[51] M. Medina-Sánchez, S. Miserere, E. Moralez-Narváez, A. Merkoçi, Biosens. Bioelectron. 2014, $54,279$. 


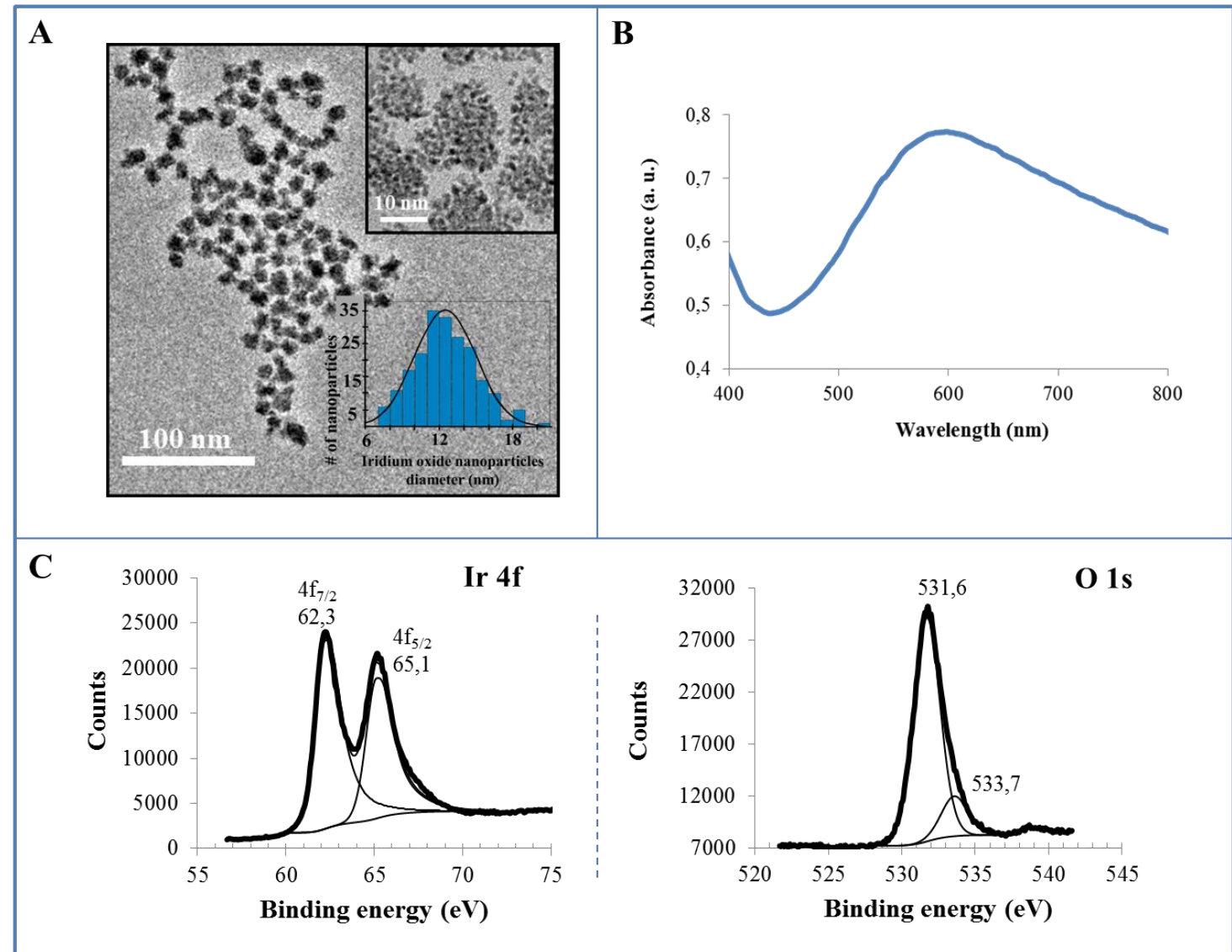

Fig. 1. Characterization of $\mathrm{IrO}_{2}$ NPs. (A) TEM micrographs, (B) UV-Vis spectrum, (C) XPS analysis: spectrum for Ir 4f line (left) and $\mathrm{O} 1 \mathrm{~s}$ line (right). 


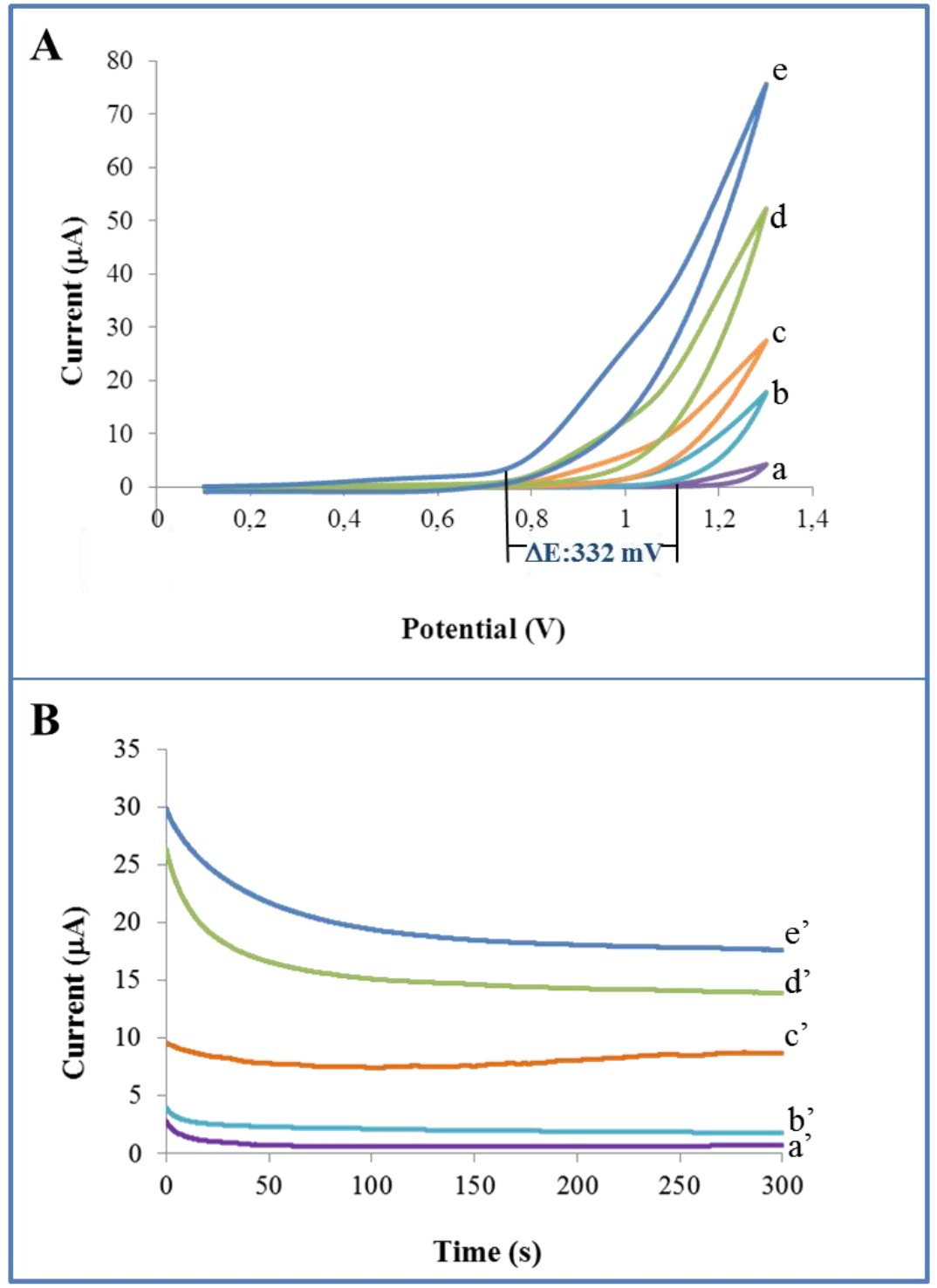

Fig. 2. Electrocatalytic activity of $\mathrm{IrO}_{2}$ NPs towards WOR. (A) Cyclic voltammograms recorded from +0.1 to $+1.3 \mathrm{~V}$ at a scan rate of $50 \mathrm{mV} / \mathrm{s}$ for $0.1 \mathrm{M}$ PBS (blank curve, a) and for increasing concentrations of $\mathrm{IrO}_{2}$ NPs in $0.1 \mathrm{M}$ PBS pH 7.4: (b) 0.7, (c) 1.8, (d) 7 and (e) $35 \mathrm{mM}$. (B) Chronoamperograms recorded at $+1.3 \mathrm{~V}$ during $300 \mathrm{~s}$ using a $0.1 \mathrm{M}$ PBS pH 7.4 (blank curve, a) and the same $\mathrm{IrO}_{2}$ NPs concentrations as detailed above (b'-e') in 0.1M PBS. 


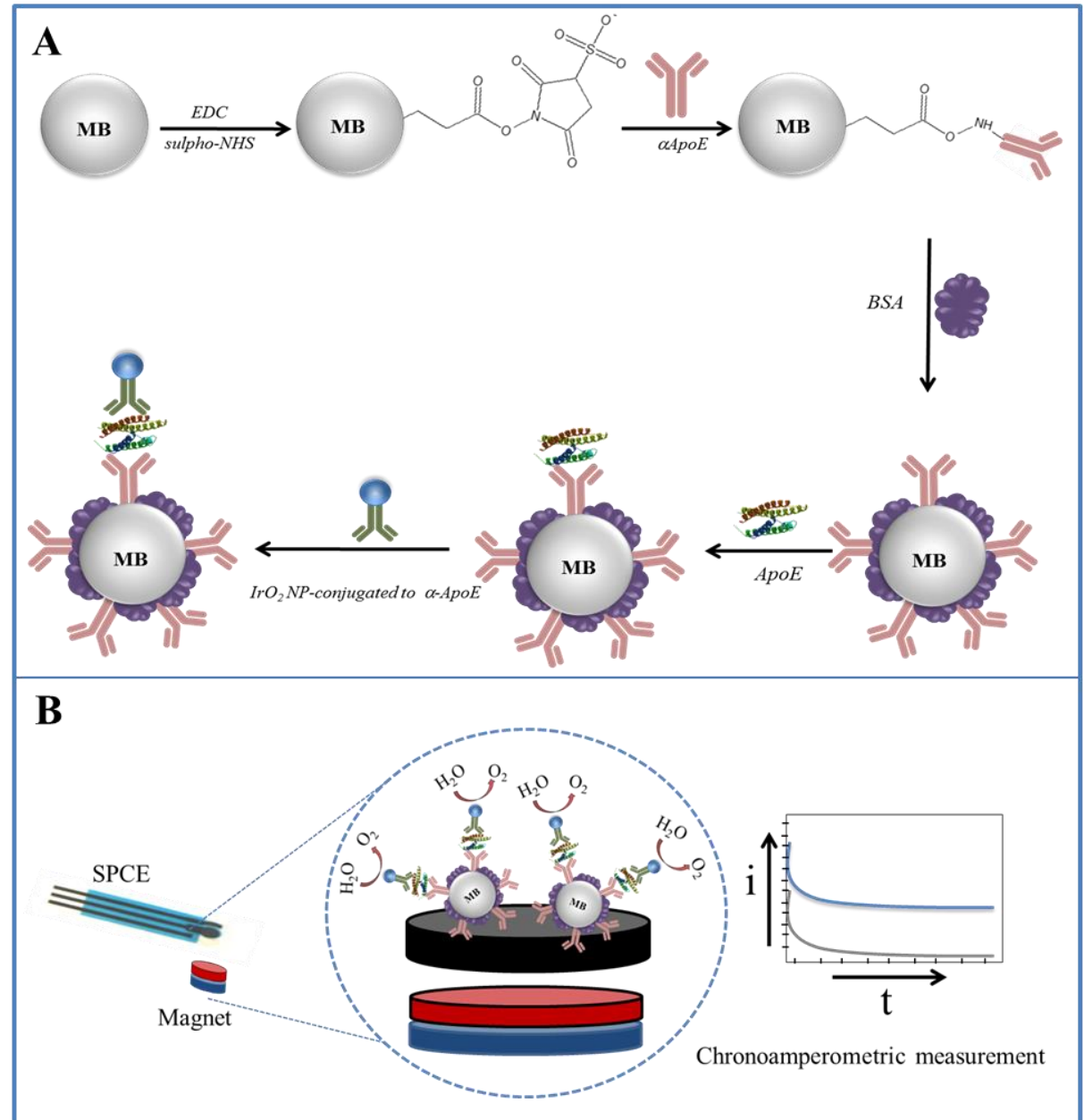

Fig. 3. Schematics, not in scale, of: (A) experimental procedure of the magnetosandwich immunoassay using $\mathrm{IrO}_{2} \mathrm{NPs}$ tags and (B) electrochemical detection procedure based on the electrocatalytic water oxidation. 


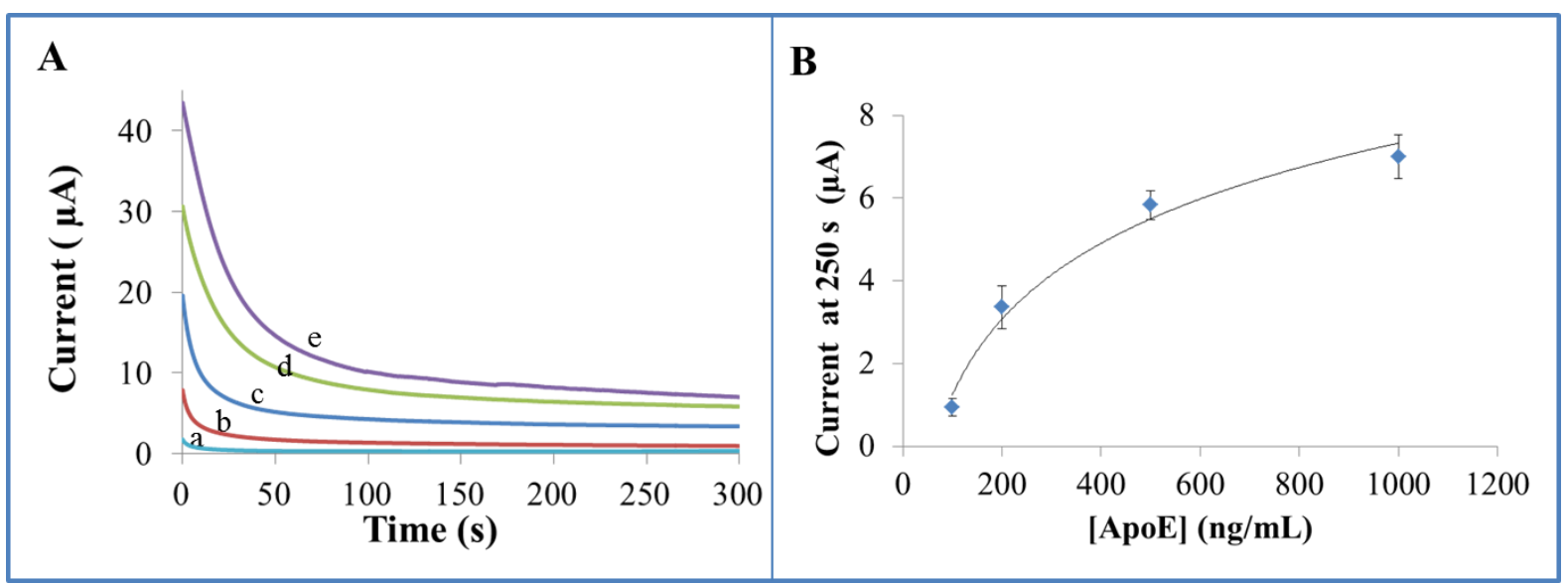

Fig. 4. (A) Chronoamperograms recorded in PBS 0.1M pH 7.4 at a fixed potential of $+1.3 \mathrm{~V}$, for a control sample (blank curve, a) and for samples containing 100 (b) , 200 (c), 500 (d) and 1000 (e) ng/mL of ApoE. (B) Relationship between the ApoE concentration and the value of the analytical signal (catalytic current recorded at 250s). Samples correspond to the magnetosandwich prepared as detailed in the experimental section. 